\title{
Evaluation of Moisture Diffusion by IR Thermography ${ }^{\dagger}$
}

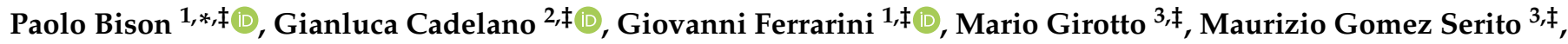 \\ Fabio Peron ${ }^{4, \ddagger}$ (1) and Monica Volinia ${ }^{3, \ddagger}$
}

1 CNR-ITC, C.so Stati Uniti 4, 35127 Padova, Italy; giovanni.ferrarini@itc.cnr.it

2 CNR-ISAC, Area della Ricerca di Roma 2, 00133 Rome, Italy; g.cadelano@isac.cnr.it

3 Politecnico di Torino, Corso Duca degli Abruzzi, 24, 10129 Torino, Italy; mario.girotto@polito.it (M.G.); maurizio.gomez@polito.it (M.G.S.); monica.volinia@polito.it (M.V.)

4 IUAV, Santa Croce, 191, 30135 Venezia VE, Italy; fperon@iuav.it

* Correspondence: paolo.bison@itc.cnr.it; Tel.: +39-049-8295735

+ Presented at the 16th International Workshop on Advanced Infrared Technology \& Applications, 26-28 October 2021; Available online: https:/ / aita2021.sciforum.net/.

$\ddagger$ These authors contributed equally to this work.

\section{check for}

updates

Citation: Bison, P.; Cadelano, G.; Ferrarini, G.; Girotto, M.; Gomez Serito, M.; Peron, F.; Volinia, M. Evaluation of Moisture Diffusion by IR Thermography. Eng. Proc. 2021, 8, 23. https://doi.org/10.3390/ engproc2021008023

Academic Editor: Davide Moroni

Published: 24 November 2021

Publisher's Note: MDPI stays neutral with regard to jurisdictional claims in published maps and institutional affiliations.

Copyright: (c) 2021 by the authors. Licensee MDPI, Basel, Switzerland. This article is an open access article distributed under the terms and conditions of the Creative Commons Attribution (CC BY) license (https:// creativecommons.org/licenses/by/ $4.0 /)$.

\begin{abstract}
It is well known that IRT is among the preferred instruments in the qualitative monitoring of humidity in buildings. The evaporation of water leads to a sink of thermal energy that eventually manifests as a decreasing of the temperature. The imaging and non-contact characteristics of IRT make the monitoring of this temperature decrease particularly easy and effective. Nonetheless, the quantitative extraction of some figures that make the qualitative observation more reliable is still an open problem.
\end{abstract}

Keywords: IR thermography; contact sponge method; humidity evaluation

\section{Introduction}

Palazzo Madama in Turin (Italy) and the castle in Rivoli (Piedmont, Italy) are a couple of outstanding buildings conceived by the architect Filippo Juvarra, who worked in Piedmont during the 18th century. The so-called Chianocco marble (see Figure 1) is one of the stones applied on the facades of such buildings. It is characterized by a good workability, and for this reason, it is preferred to other stones.

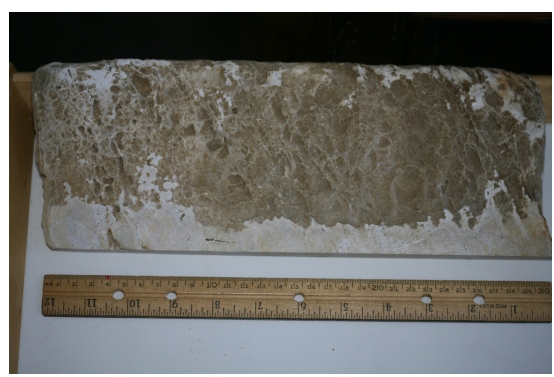

Figure 1. A sample of Chianocco marble used by the architect Filippo Juvarra in the 18th century on the facades of both Palazzo Madama (Turin, Italy) and the Castle in Rivoli (Piedmont, Italy).

On the other hand, such material is often inhomogeneous and its porosity could be quite large, that leads, over the years, to a degradation that is sometimes severe. Hence, the necessity of restoration, which often consists in spreading a protective hydrophobic layer on the surface. It is the interest of the restorers to find methods that are easy and fast in detecting the state of those stones, if they were already treated and what is the level of their porosity and, eventually, how much humidity they absorb. It is well known that InfraRed Thermography (IRT) is among the preferred instruments in the qualitative monitoring of humidity in buildings $[1,2]$. The evaporation of water leads to a sink of 
thermal energy that eventually manifests as a decreasing of temperature. The imaging and non-contact characteristics of IRT makes the monitoring of this temperature decrease particularly easy and effective. Nonetheless, the quantitative extraction of some figures that make the qualitative observation more reliable is still an open problem [3,4].

One of the first attempts to make the quantitative assessment of the amount of water absorbed by porous materials was based on the idea that water, which possesses a very high heat capacity, significantly changes the thermal inertia of the material itself. Active thermography was used by heating the surface of the moistened porous material by lamps. The zones with higher water contents are supposed to react with a lower increase of temperature in comparison with the drier ones $[5,6]$. On the other hand, the increase of temperature increases the evaporation as well, resulting in a further attenuation of the temperature increase and in a possible overestimation of the water content. Other attempts of enhancing the evaporation effect in a controlled way by forced ventilation have been proposed [7]. Here, the increased thermal inertia, due to the water absorbed by the porous material, acts as a dumping effect in the decreasing of temperature due to the evaporation enhanced by the forced ventilation.

The contact sponge method $[8,9]$ to measure the water absorption is attracting the attention of the restorers for its easy applicability in situ [10,11]. Following the work of Ludwig et al. [12], the novelty proposed in this work is that of monitoring the effect of the water evaporation, during and after the application of the contact sponge, by IRT. IRT monitors the evolution of the diffusion of water in the porous material, both in time and space by collecting a sequence of IR images during the process. From the experimental point of view, the first attempt was done in situ. Later on, to understand better the phenomenon, several tests were carried out in laboratory conditions using specimens of the same materials already tested on the facades of the analyzed buildings. The data obtained both in situ and in laboratory are quite interesting and show the effectiveness of the thermographic instrument to analyze the porosity of such stones. Indeed, it was possible to see qualitatively that, in the same stone, at a few centimeters of distance, areas coexist that are characterized by a strong evaporation, while, very close to them, other areas are essentially inert.

To better understand the phenomena, it was planned to carry on some experiments on porous materials that are much more homogeneous in respect to the Chianocco marble. A fired clay brick and a sand stone pietra serena have been used to apply the contact sponge technique and to monitor the induced effects by IRT in a controlled environment.

\section{Modeling}

The contact sponge method consists of a contact cup that contains the sponge, whose thickness is slightly greater than the height of the cup. The cup containing the humid sponge is pressed manually on the surface of the material until the border of the cup is in contact with the surface. That results in a fairly reproducible action. After a predefined amount of time, for example $90 \mathrm{~s}$, the sponge is removed from the surface and the weight of the sponge itself is compared with that obtained before the application. The difference is the amount of water absorbed by the surface of the material, which can be described by the following equation:

$$
W_{a}=\frac{m_{i}-m_{f}}{A \cdot \delta t}
$$

where $W_{a}$ is the water absorbed per unit area and unit time, $m_{i}$ and $m_{f}$ are initial and final weights of the sponge, respectively, $A$ is the area of the sponge and $\delta t$ is the time of contact between the sponge and the material.

Following the application of the sponge, it is possible to monitor the surface by IRT. The area corresponding to the zone of the sponge application is clearly visible due to the strong evaporation effect (see Figure 2 left). The diffusion of water through the pores of the stones (eventually coupled with the heat conduction as a consequence of the heat sink due to the evaporation) can be monitored as well by collecting a sequence of IR images at 
prescribed time intervals (see Figure 2 right, where some temperature profiles crossing the sponge area are shown).
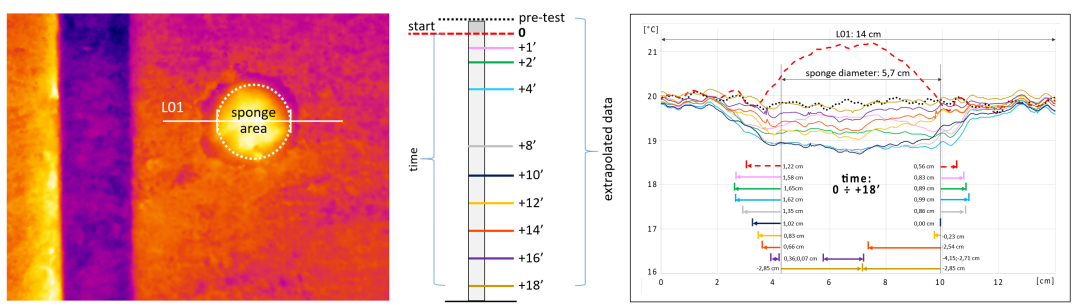

Figure 2. IR image of a piece of marble after the humid sponge application. The image was taken during the in situ survey. On the right, some temperature profiles crossing the sponge area are shown.

It is well known that heat diffusion and water diffusion can be described by similar differential equation:

$$
\frac{\partial X}{\partial t}-D \times \nabla X=0
$$

where $X$ is either temperature $T([K]))$ or concentration $\phi\left(\left[\mathrm{kg} \mathrm{m}^{-3}\right]\right), t$ is time ([s]) and $D\left(\left[\mathrm{~m}^{2} \mathrm{~s}^{-1}\right]\right)$ is either thermal diffusivity or water diffusivity. Therefore, many solutions available for the heat conduction can be utilized for the water diffusion. An example is the estimation of the thermal diffusivity by using the method introduced by Philippi et al. [13]. It consists in generating a localized pulse of energy on the surface of the sample and in analyzing the components of the spatial Fourier Transform in time. The logarithm of the amplitude of each component can be fitted in time by a straight line whose slope represents the thermal diffusivity times the square of the spatial frequency. It is evident that the sponge method generates a spatial localized perturbation that is monitored by its effect due to the evaporation. Evidently, the sink of heat generates a heat perturbation as well. Therefore, the two phenomena, the heat diffusion and the water diffusion, coexist. On the other hand, if the two diffusion processes works on two different time scales, it is expected that they could be decoupled.

\section{Results}

A piece of fired clay brick was used to test the applicability of the water diffusion evaluation. Its thermal conductivity was measured by Hot Disk TPS2500 apparatus, the specific heat by Netzsch STA 449 C and the density by hydrostatic balance. Results are shown in Table 1, together with the related thermal diffusivity.

Table 1. Thermal properties of the fired clay brick used in the experiment.

\begin{tabular}{|c|c|c|c|}
\hline $\begin{array}{l}\text { Thermal Conductivity } \\
\qquad \mathrm{W} \mathrm{m} \mathbf{m}^{-1} \mathrm{~K}^{-1}\end{array}$ & $\begin{array}{c}\text { Specific Heat } \\
\mathrm{J} \mathrm{kg}^{-1} \mathrm{~K}^{-1}\end{array}$ & $\begin{array}{l}\text { Density } \\
\mathrm{kg} \mathrm{m}^{-3}\end{array}$ & $\begin{array}{l}\text { Thermal Diffusivity } \\
\qquad \mathrm{m}^{2} \mathrm{~s}^{-1}\end{array}$ \\
\hline 0.56 & 840 & 1613 & $4.1 \times 10^{-7}$ \\
\hline
\end{tabular}

The sponge was applied on the surface of the brick for $220 \mathrm{~s}$. After removing the sponge, the IR camera collects a sequence of images that are finally processed according to the algorithm described above. The results are shown in Figure 3 where, on the left, is shown one image in the sequence with a clear evidence of the circular sponge contour. On the right, the results obtained after taking the logarithm of the Discrete Cosine Transform (DCT) are plotted. The slope of the straight line fitting the data (green circle) gives the moisture diffusivity value that is $D=5.3 \times 10^{-9}$ and it is consistent with the values obtained in the detailed work of Pel and coauthors [14] for clay bricks. It must be remarked that it is two order of magnitude lower than the one due to the thermal conduction and reported in Table 1. 

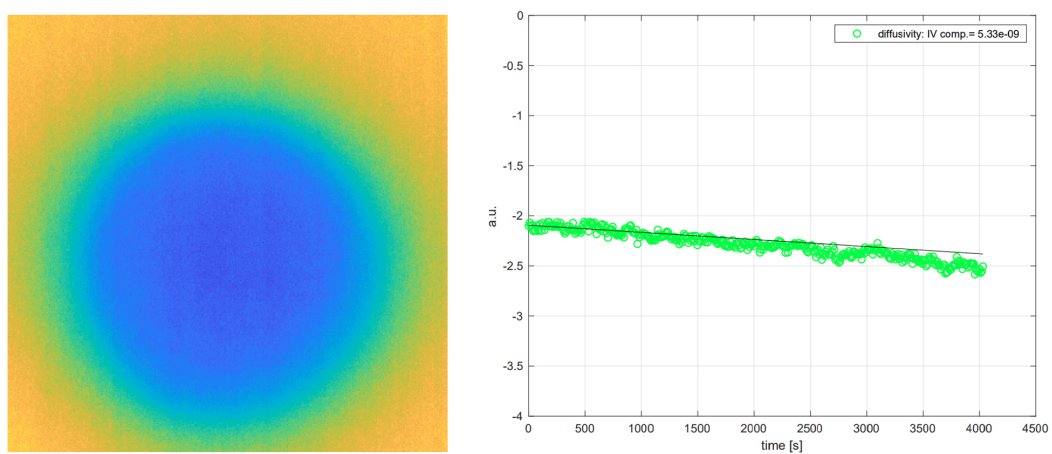

Figure 3. On the left an IR image of the brick surface after the application of the sponge. On the right the logarithm of the profile of the Discrete Cosine Transform and the fit of data that eventually furnish the value of the moisture diffusivity.

\section{Conclusions}

IRT is utilized to monitor the effects of the contact sponge. The variation of temperature in space and time are analyzed with an algorithm that was formerly presented to evaluate the in-plane thermal diffusivity. In this case, the phenomena under test are both thermal diffusion and moisture diffusion. The preliminary results show that the diffusion of moisture, even though taken into account through its thermal effect, is two order of magnitude lower than its thermal counterpart.

Institutional Review Board Statement: Not applicable.

Informed Consent Statement: Not applicable.

Data Availability Statement: Data can be provided on request, to be submitted to the corresponding author.

Conflicts of Interest: The authors declare no conflict of interest.

\section{References}

1. Marshall, S.J. Detecting moisture in buildings using infrared thermography. Proc. SPIE 1981, 111-117.

2. Lyberg, M.D.; Mattsson, M.; Sundberg, J. Detection of moisture damage in buildings using thermography. Proc. SPIE 1990, 100-105. [CrossRef]

3. Grinzato, E.; Ludwig, N.; Cadelano, G.; Bertucci, M.; Gargano, M.; Bison, P. Infrared thermography for moisture detection: A laboratory study and in situ test. Mater. Eval. 2011, 69, 97-104.

4. Bison, P.; Cadelano, G.; Capineri, L.; Capitani, D.; Casellato, U.; Faroldi, P.; Grinzato, E.; Ludwig, N.; Olmi, R.; Priori, S.; et al. Limits and advantages of different techniques for testing moisture content in masonry. Mater. Eval. 2011, 69, 111-116.

5. Baggio, P.; Bison, P.G.; Bonacina, C.; Bressan, C.; Grinzato, E. Thermal inertia evaluation in porous material by multispectral optical analysis. In Proceedings of the XVIII I.I.R. International Congress, Montreal, QC, Canada, 10-17 August 1991; pp. 694-698.

6. Bison, P.G.; Bressan, C.; Grinzato, E. Automatic equipment for water content measurement on porous materials by means of multispectral analysis. In Proceedings of the Workshop on Advanced Infrared Technology and Applications, CNR-IROE, Florence, Italy, 13-14 April 1992; pp. 375-386.

7. Bison, P.; Cadelano, G.; Grinzato, E. Thermographic Signal Reconstruction with periodic temperature variation applied to moisture classification. Quant. Infrared Thermogr. J. 2011, 8, 221-238. [CrossRef]

8. UNI 11432:2011—Beni culturali-Materiali lapidei naturali ed artificiali-Misura della capacità di assorbimento di acqua mediante spugna di contatto. 2011. Available online: http://store.uni.com/catalogo/uni-11432-2011?__store=en\&josso_back_ to $=$ http $\% 3 \mathrm{~A} \% 2 \mathrm{~F} \% 2$ Fstore.uni.com\%2Fjosso-security-check.php\&josso_cmd=login_optional\&josso_partnerapp_host=store.uni. com\&__from_store=it (accessed on 1 October 2021).

9. Pardini, C.; Tiano, P. Valutazione In Situ dei Trattamenti Protettivi per il Materiale Lapideo, Proposta di una Nuova Semplice Metodologia. ARKOS. 2004, Volume 5, pp. 30-36. Available online: https://www.arkoslight.com/en/ (accessed on 1 October 2021).

10. Vandevoorde, D.; Pamplona, M.; Schalm, O.; Vanhellemont, Y.; Cnudde, V.; Verhaeven, E. Contact sponge method: Performance of a promising tool for measuring the initial water absorption. J. Cult. Herit. 2009, 10, 41-47. [CrossRef]

11. Ribeiro, T.; Oliveira, D.V.; Bracci, S. The Use of Contact Sponge Method to Measure Water Absorption in Earthen Heritage Treated with Water Repellents. Int. J. Archit. Herit. 2020. [CrossRef] 
12. Ludwig, N.; Rosina, E.; Sansonetti, A. Evaluation and monitoring of water diffusion into stone porous materials bymeans of innovative IR thermography techniques. Measurement 2018, 118, 348-353. [CrossRef]

13. Philippi, I.; Batsale, J.C.; Maillet, D.; Degiovanni, A. Measurement of thermal diffusivities through processing of infrared images. Rev. Sci. Instrum. 1995, 66, 182-192. [CrossRef]

14. Pel, L.; Brocken, H.; Kopinga, K. Determination of moisture diffusivity in porous media using moisture concentration profiles. Int. J. Heat Mass Transf. 1996, 39, 1273-1280. [CrossRef] 